\title{
SSI AND SSSI EFFECTS IN SEISMIC ANALYSIS OF TWIN BUILDINGS: DISCRETE MODEL CONCEPT
}

\author{
Sadegh Naserkhaki ${ }^{1}$, Hassan Pourmohammad ${ }^{2}$ \\ ${ }^{1}$ Sama Technical and Vocational Training College, Islamic Azad University, Karaj Branch, Karaj, Iran \\ ${ }^{2}$ Department of Civil Engineering, Faculty of Engineering, Islamic Azad University, \\ Karaj Branch, Karaj, Iran \\ E-mails: ${ }^{1}$ snkhaki@gmail.com (corresponding author); 2 poormohammad72@yahoo.com \\ Received 23 Feb. 2011; accepted 24 May 2011
}

\begin{abstract}
This paper presents a numerical study of soil-structure interaction (SSI) and structure-soil-structure interaction (SSSI) effects on response of twin buildings during earthquake excitations. The buildings are modeled as shear buildings and the soil is simulated by a discrete model representing a visco-elastic half-space subjected to earthquake acceleration. Equation of motion of twin buildings with different conditions, fixed based (FB), SSI and SSSI, are developed via an analytical procedure and solved numerically. Buildings responses are evaluated for aforementioned three conditions considering various soil types and compared together. One must say that soil causes change in distribution of responses throughout the buildings while ignoring soil interaction may lead to detrimental effects on buildings. Anyway, interaction between twin buildings with SSSI condition slightly mitigates soil unfavorable effects compare to one building with SSI condition. In addition, it is found that influence of soil is very significant for soft to stiff soils whereas negligible for hard soils.
\end{abstract}

Keywords: soil-structure interaction, structure-soil-structure interaction, seismic analysis, discrete model.

\section{Introduction}

The building generally interacts with underlying soil so it would be more rational to analyze the building and underlying soil simultaneously. Both buildings and soil are involved in earthquake excitation and deformation of one affects the other (soil-structure interaction, SSI). SSI effects of buildings have been widely treated by former researchers (Parmelee et al. 1969; Gupta, Trifunac 1991; Shakib, Fuladgar 2004; Dutta et al. 2004). An experimental test carried out by Gallipoli et al. (2006) showed that buildings are able to modify substantially the freefield ground motion in their proximity. Anyhow, alteration of soil deformation in the neighborhood of a building due to feedback of the building's own inertia (Kausel 2010) is a phenomenon that has been less considered previously. This is called structure-soil-structure interaction (SSSI) between two/group of adjacent buildings.

A sensitivity study for the interaction effects of adjacent structures of nuclear power plants caused by horizontal seismic excitation has been performed by Matthees and Magiera (1982). It has been shown that the interaction phenomena can contribute to the response of structures to such a large extent that it cannot be disregarded.

Modeling of adjacent buildings attached to underlying soil has been previously done by using FEM-BEM methods (Wang, Schmid 1992; Lehmann, Antes 2001; Chouw 2002; Padrón et al. 2009). In the numerical work carried out by Wang and Schmid (1992) to study SSSI condition between adjacent buildings, effects of some parameters like separation distance, direction of alignment between two foundations, bedrock, natural frequency of the system and the location of load on the dynamic responses of the structures have been investigated through a FEM-BEM method. But a harmonic load was applied to the system and arbitrary variation of earthquake excitations did not accounted in their study. Lehmann and Antes (2001) proposed a hybrid model to evaluate response of adjacent buildings considering soil effects. Despite of valuable efforts to validate the model, SSSI effects was not paid attention in this research. Chouw (2002) evaluated response of two adjacent buildings that were subjected to building pounding during earthquakes. Pounding of building were more likely to happen when SSSI condition was considered. This was because of larger displacements produced due to SSSI effect. The research by Padrón et al. (2009) has the advantage of taking into account group of nearby one story buildings supported by pile-foundations. SSSI effect was found to be very important depending on separation distance and dynamic characteristics of buildings. However, effects of SSSI on multistory buildings with shallow foundations were not addressed in this work.

On the other hand, analytical approaches have been proposed to simulate both building and soil (Novak, El Hifnawy 1983; Rohanimanesh 1994; Rambabu, Allam 2007). The building is modeled as a shear building and the soil is simulated as a discrete model with mass, damping and stiffness representing a visco-elastic half-space. This model is simple and efficient and can be easily 
applied to a SSSI system. However, previous studies used this model to analyze SSI condition for one building and where the adjacent buildings were considered, coupling of buildings through the soil was not accounted. Furthermore, dynamics of two adjacent foundations resting on a visco-elastic half-space (foundation-soil-foundation interaction) has been studied by Mulliken and Karabalis (1998) and the coupling terms between two adjacent foundations were defined.

With respect to aforementioned advantages of discrete model in seismic analysis of buildings with soil effects considerations, it is much worth analyzing the building and soil via this method. Therefore, combination of analytical approach to analyze multistory shear buildings and discrete model of soil in a way the buildings are coupled through the soil is the aim of this paper. Hence, seismic behavior of buildings with different conditions, FB, SSI and SSSI, can be analyzed, compared and discussed. Effect of different soil types from soft soil to hard soils or soft rocks is also investigated.

\section{Analytical concept}

\subsection{Building with fixed based (FB)}

The building is assumed as a shear building with concentrated mass (m), viscous damper (c) and linear spring (k) at each story. Governing equation of motion of this building which is excited by earthquake acceleration of $\ddot{u}_{g}(t)$ is:

$$
\mathbf{m}_{b} \ddot{\mathbf{u}}_{b}+\mathbf{c}_{b} \dot{\mathbf{u}}_{b}+\mathbf{k}_{b} \mathbf{u}_{b}=-\mathbf{m}_{b} \mathbf{v}_{b} \ddot{u}_{g}(t),
$$

where $\mathbf{m}_{b}$ and $\mathbf{k}_{b}$ are $n$ by $n$ mass and stiffness matrices of the building, respectively ( $n$ is number of stories of the building). $\mathbf{c}_{b}$ is Rayleigh damping matrix which is proportional to mass and stiffness matrices:

$$
\mathbf{c}_{b}=a_{0} \mathbf{m}_{b}+a_{1} \mathbf{k}_{b},
$$

$\mathrm{a}_{0}$ and $\mathrm{a}_{1}$ are Rayleigh coefficients which can be determined from buildings modal damping ratios and frequen- cies. Also, $\ddot{\mathbf{u}}_{b}, \dot{\mathbf{u}}_{b}, \mathbf{u}_{\boldsymbol{b}}$ and $\mathbf{v}_{\boldsymbol{b}}$ are $n$ by 1 acceleration, velocity, displacement and influence vectors, respectively:

$$
\begin{aligned}
\ddot{\mathbf{u}}_{b}^{T} & =\left\{\begin{array}{lllll}
\ddot{u}_{1} & \ldots & \ddot{u}_{i} & \ldots & \ddot{u}_{n}
\end{array}\right\} ; \\
\dot{\mathbf{u}}_{b}^{T} & =\left\{\begin{array}{lllll}
\dot{u}_{1} & \ldots & \dot{u}_{i} & \ldots & \dot{u}_{n}
\end{array}\right\} ; \\
\mathbf{u}_{b}^{T} & =\left\{\begin{array}{lllll}
u_{1} & \ldots & u_{i} & \ldots & u_{n}
\end{array}\right\} ; \\
\mathbf{v}_{b}^{T} & =\left\{\begin{array}{lllll}
1 & \ldots & 1 & \ldots & 1
\end{array}\right\} .
\end{aligned}
$$

\subsection{Building with soil effects}

In numerical analysis, underlying soil can be modeled by a discrete model (mass, damping and stiffness model) representing homogeneous, isotropic, linear visco-elastic halfspace (Figs 1 and 2). SSI effect is result of modeling of soil beneath one building (Fig. 1) while SSSI effect comes from modeling of soil beneath twin buildings (Fig. 2).

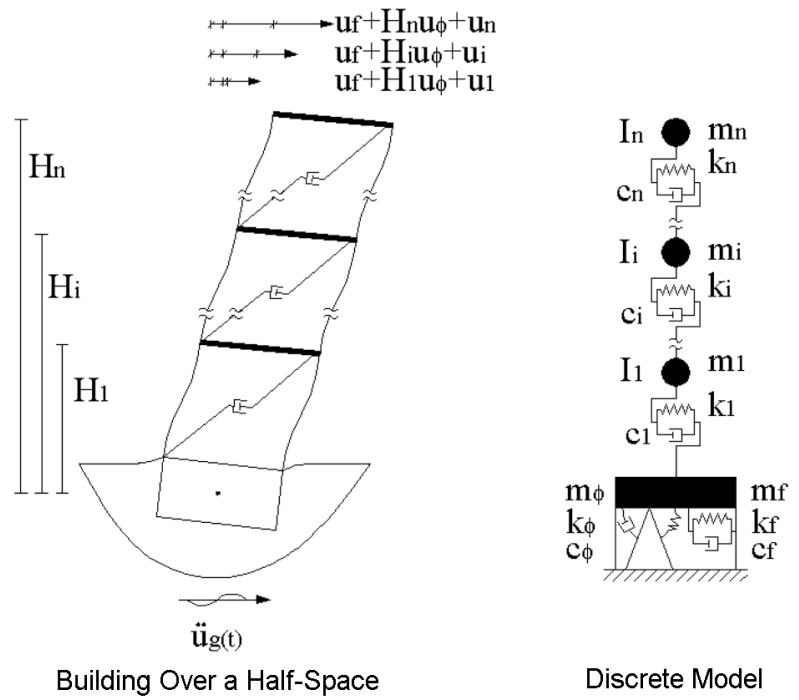

Fig. 1. Soil-structure interaction of one building

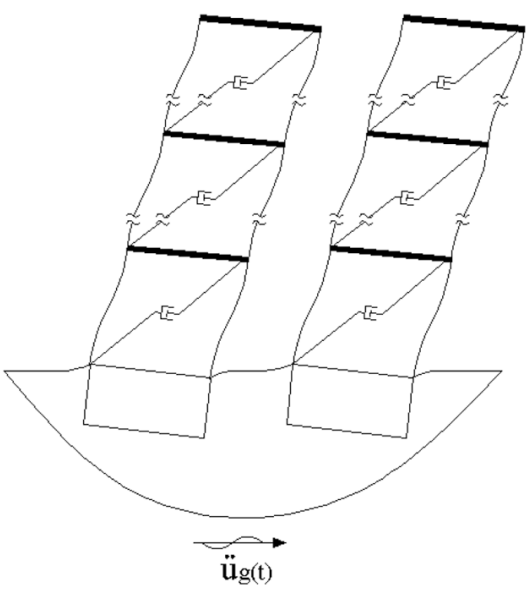

Twin Buildings Over a Half-Space

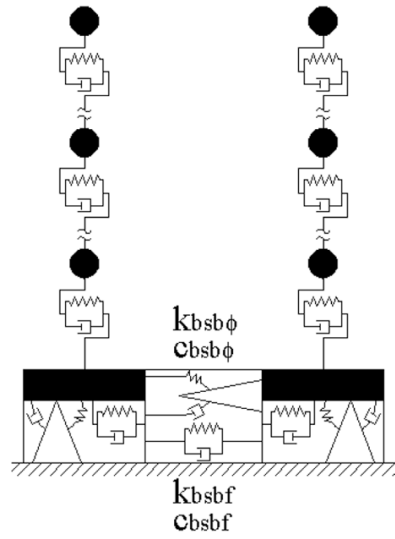

Discrete Model

Fig. 2. Structure-soil-structure interaction of twin buildings 


\subsubsection{SSI effect}

Movement of soil beneath a building due to earthquake excitation can be introduced by two displacements: horizontal and rocking. Based on the principal of discrete model mass of soil plus mass of foundation move due to earthquake excitation while elastic spring resists against the movement and viscous damper dissipates the energy of excitation. Two equations of equilibrium must be satisfied because of two additional displacements; equilibrium of horizontal forces and equilibrium of moment around the center of gravity of the soil. Adding these two equations to equation of motion of building (Eq. (1)) gives:

$$
\mathbf{m}_{s b} \ddot{\mathbf{u}}_{s b}+\mathbf{c}_{s b} \dot{\mathbf{u}}_{s b}+\mathbf{k}_{s b} \mathbf{u}_{s b}=-\left(\mathbf{m}_{s b} \mathbf{v}_{s b}+\mathbf{v}_{f s b}\right) \ddot{u}_{g}(t) .
$$

This equation includes both building and soil displacements which can be expanded as:

$$
\begin{gathered}
{\left[\begin{array}{cc}
\mathbf{m}_{s} & \mathbf{m}_{s b} \\
\mathbf{m}_{s b} & \mathbf{m}_{b}
\end{array}\right]\left\{\begin{array}{l}
\ddot{\mathbf{u}}_{s} \\
\ddot{\mathbf{u}}_{b}
\end{array}\right\}+\left[\begin{array}{cc}
\mathbf{c}_{s} & \mathbf{0} \\
\mathbf{0} & \mathbf{c}_{b}
\end{array}\right]\left\{\begin{array}{c}
\dot{\mathbf{u}}_{s} \\
\dot{\mathbf{u}}_{b}
\end{array}\right\}+\left[\begin{array}{cc}
\mathbf{k}_{s} & \mathbf{0} \\
\mathbf{0} & \mathbf{k}_{b}
\end{array}\right]\left\{\begin{array}{l}
\mathbf{u}_{s} \\
\mathbf{u}_{b}
\end{array}\right\}} \\
=-\left(\left[\begin{array}{cc}
\mathbf{m}_{s} & \mathbf{m}_{s b} \\
\mathbf{m}_{s b} & \mathbf{m}_{b}
\end{array}\right]\left\{\begin{array}{c}
\mathbf{0} \\
\mathbf{v}_{b}
\end{array}\right\}+\left\{\begin{array}{c}
\mathbf{v}_{s} \\
\mathbf{0}
\end{array}\right\}\right) \ddot{y}_{g}(t) .
\end{gathered}
$$

Eq. (8) includes $n+2$ coupled equations of motion. $\mathbf{m}_{s}, \mathbf{c}_{\boldsymbol{s}}$ and $\mathbf{k}_{\boldsymbol{s}}$ are 2 by 2 mass, damping and stiffness matrices of soil, respectively and $\ddot{\mathbf{u}}_{s}, \dot{\mathbf{u}}_{s}, \mathbf{u}_{s}$ and $\mathbf{v}_{\boldsymbol{s}}$ are 2 by 1 acceleration, velocity, displacement and influence vectors of soil, respectively. $\mathbf{m}_{s b}$ and $\mathbf{m}_{b s}$ are 2 by $n$ and $n$ by 2 SSI matrices, respectively:

$$
\begin{gathered}
\mathbf{m}_{s}=\left[\begin{array}{cc}
m_{\phi}+\sum_{i=1}^{n} H_{i}^{2} m_{i}+I_{i} & \sum_{i=1}^{n} H_{i} m_{i} \\
\sum_{i=1}^{n} H_{i} m_{i} & m_{f}+\sum_{i=1}^{n} m_{i}
\end{array}\right] ; \\
\mathbf{c}_{s}=\left[\begin{array}{cc}
c_{\phi} & 0 \\
0 & c_{f}
\end{array}\right] ; \\
\mathbf{k}_{s}=\left[\begin{array}{cc}
k_{\phi} & 0 \\
0 & k_{f}
\end{array}\right] ;
\end{gathered}
$$

$$
\begin{aligned}
& \ddot{\mathbf{u}}_{s}^{T}=\left\{\begin{array}{ll}
\ddot{u}_{\phi} & \ddot{u}_{f}
\end{array}\right\} ; \\
& \dot{\mathbf{u}}_{s}^{T}=\left\{\begin{array}{ll}
\dot{u}_{\phi} & \dot{u}_{f}
\end{array}\right\} ; \\
& \mathbf{u}_{s}^{T}=\left\{\begin{array}{ll}
u_{\phi} & u_{f}
\end{array}\right\} \text {; } \\
& \mathbf{v}_{s}^{T}=\left\{\begin{array}{ll}
0 & m_{f}
\end{array}\right\} ; \\
& \mathbf{m}_{s b}=\mathbf{m}_{b s}^{T}=\left[\begin{array}{ccccc}
H_{1} m_{1} & \ldots & H_{i} m_{i} & \ldots & H_{n} m_{n} \\
m_{1} & \ldots & m_{i} & \ldots & m_{n}
\end{array}\right],
\end{aligned}
$$

where $m_{\phi}, c_{\phi}$ and $k_{\phi}$ are mass, damping and stiffness of rocking component of soil, respectively, $m_{f}, c_{f}$ and $k_{f}$ are mass, damping and stiffness of horizontal component of soil, respectively and $I$ is mass moment of inertia of the building story. Masses of soil model are virtual masses of soil plus mass of rigid foundation itself. Stiffness and damping coefficients of the soil model are frequency dependent parameters. Nevertheless, several numerical efforts have been done to correlate these dynamic properties to static properties of soil in time domain (Gazetas 1983). Advantage of introducing soil parameters in time domain is to describe soil model by basic constants of soil such as shear modulus of soil $(G)$, shear wave velocity of soil $\left(V_{s}\right)$ and poisson's ratio of soil $(v)$ which could be easily obtained by experiment and width of foundation (2a). Mulliken and Karabalis (1998) gathered and compared different formulas had been developed for soil model and proposed the values which best fit the various available data (Table 1).

\subsubsection{SSSI effect}

Twin buildings are coupled through the soil as shown in Fig. 2. Coupling of twin buildings could be introduced by discrete soil stiffness and damping coefficient (Mulliken, Karabalis 1998). SSSI effect produces a new equation of motion for twin buildings which is modification of Eq. (7):

$$
\mathbf{m}_{b s b} \ddot{u}_{b s b}+\mathbf{c}_{b s b} \dot{\mathbf{u}}_{b s b}+\mathbf{k}_{b s b} \mathbf{u}_{b s b}=-\left(\mathbf{m}_{b s b} \mathbf{v}_{b s b}+\mathbf{v}_{f b s b}\right) \ddot{u_{g}}(t) .
$$

Table 1. Values for SSI parameters (Mulliken, Karabalis 1998)

\begin{tabular}{l|c|c}
\hline \multirow{2}{*}{ mass } & Horizontal & Rocking \\
\hline damping & $m_{f}=4.37 \frac{(1-v)}{(7-8 v)} \frac{G a^{3}}{V_{s}^{2}}$ & $m_{\phi}=1.24 \frac{1}{(1-v)} \frac{G a^{5}}{V_{s}^{2}}$ \\
\hline stiffness & $c_{f}^{*}=1.50 \frac{1}{(2-v)} \frac{G a^{2}}{V_{s}}$ & $c_{\phi}=2.40 \frac{1}{(1-v)} \frac{G a^{4}}{V_{s}}$ \\
\hline
\end{tabular}

Note: $c_{f}^{*}$ is radiation damping of the soil. 
Expansion of Eq. (17) gives better demonstration of equation of motion of twin buildings coupled through the soil. The coupling is taken place via SSSI terms which are off diagonal components of stiffness and damping matrices:

$$
\begin{aligned}
& {\left[\begin{array}{rlrl}
\mathbf{m}_{l s} & \mathbf{m}_{l s b} & \mathbf{0} & \mathbf{0} \\
\mathbf{m}_{l b s} & \mathbf{m}_{l b} & \mathbf{0} & \mathbf{0} \\
\mathbf{0} & \mathbf{0} & \mathbf{m}_{r s} & \mathbf{m}_{r s b} \\
\mathbf{0} & \mathbf{0} & \mathbf{m}_{r b s} & \mathbf{m}_{r b}
\end{array}\right]\left\{\begin{array}{c}
\ddot{\mathbf{u}}_{l s} \\
\ddot{\mathbf{u}}_{l b} \\
\ddot{\mathbf{u}}_{r s} \\
\ddot{\mathbf{u}}_{r b}
\end{array}\right\}} \\
& +\left[\begin{array}{cccc}
\mathbf{c}_{l s} & \mathbf{0} & -\mathbf{c}_{b s b} & \mathbf{0} \\
\mathbf{0} & \mathbf{c}_{l b} & \mathbf{0} & \mathbf{0} \\
-\mathbf{c}_{b s b} & \mathbf{0} & \mathbf{c}_{r s} & \mathbf{0} \\
\mathbf{0} & \mathbf{0} & \mathbf{0} & \mathbf{c}_{r b}
\end{array}\right]\left\{\begin{array}{l}
\dot{\mathbf{u}}_{l s} \\
\dot{\mathbf{u}}_{l b} \\
\dot{\mathbf{u}}_{r s} \\
\dot{\mathbf{u}}_{r b}
\end{array}\right\} \\
& +\left[\begin{array}{cccc}
\mathbf{k}_{l s} & \mathbf{0} & -\mathbf{k}_{b s b} & \mathbf{0} \\
\mathbf{0} & \mathbf{k}_{l b} & \mathbf{0} & \mathbf{0} \\
-\mathbf{k}_{b s b} & \mathbf{0} & \mathbf{k}_{r s} & \mathbf{0} \\
\mathbf{0} & \mathbf{0} & \mathbf{0} & \mathbf{k}_{r b}
\end{array}\right]\left\{\begin{array}{l}
\mathbf{u}_{l s} \\
\mathbf{u}_{l b} \\
\mathbf{u}_{r s} \\
\mathbf{u}_{r b}
\end{array}\right\} \\
& =-\left(\left[\begin{array}{cccc}
\mathbf{m}_{l s} & \mathbf{m}_{l s b} & \mathbf{0} & \mathbf{0} \\
\mathbf{m}_{l b s} & \mathbf{m}_{l b} & \mathbf{0} & \mathbf{0} \\
\mathbf{0} & \mathbf{0} & \mathbf{m}_{r s} & \mathbf{m}_{r s b} \\
\mathbf{0} & \mathbf{0} & \mathbf{m}_{r b s} & \mathbf{m}_{r b}
\end{array}\right]\left\{\begin{array}{c}
\mathbf{0} \\
\mathbf{v}_{l b} \\
\mathbf{0} \\
\mathbf{v}_{r b}
\end{array}\right\}\right. \\
& +\left\{\begin{array}{c}
\mathbf{v}_{l s} \\
\mathbf{0} \\
\mathbf{v}_{r s} \\
\mathbf{0}
\end{array}\right\} \ddot{u}_{g}(t),
\end{aligned}
$$

where $l$ stands for left building and $r$ denotes right buildings. SSSI terms are:

$$
\begin{aligned}
\mathbf{c}_{b s b} & =\left[\begin{array}{cc}
c_{b s b \phi} & 0 \\
0 & c_{b s b f}
\end{array}\right] ; \\
\mathbf{k}_{b s b} & =\left[\begin{array}{cc}
k_{b s b \phi} & 0 \\
0 & k_{b s b f}
\end{array}\right] .
\end{aligned}
$$

SSSI stiffness and damping coefficients have been proposed by Mulliken and Karabalis (1998). For square foundations with width of $2 a$ and separation distance of $d$ resting on an elastic half-space they proposed values tabulated in Table 2.

\section{Numerical study}

Seismic analysis of twin buildings during earthquake excitation requires to solve a second order linear ordinary differential equation (Eq. (14)). Step by step procedure is a general approach for dynamic response analysis, and it is well suited to seismic analysis of this type of problem. Newmark (1959) linear acceleration step by step method is simple, accurate and computationally efficient hence is employed in this numerical study. Thus, a computer program including all formulations and procedures involving in seismic analysis of twin buildings considering soil effects has been written to assist us during the analyses.

The buildings under study are 7 -story buildings with mass of $100 \times 10^{3}(\mathrm{~kg})$ per story and constant stiffness of $173 \times 10^{6}(\mathrm{~N} / \mathrm{m})$. A damping ratio of $5 \%$ has been considered to account for energy dissipation during building vibration. Soil types are chosen between soft to hard soils within the range of 160 to $800(\mathrm{~m} / \mathrm{s})$ of shear wave velocity of soil. Among different earthquake accelerations which have been used in the analyses, acceleration time history of well known El-Centro earthquake (I-ELC180 1940) with PGA equal to $0.313 \mathrm{~g}$ is presented in the numerical study.

\subsection{Soil effects on building period}

Building period is a significant dynamic property of building which can help to predict seismic behavior of building during earthquake excitations. For instance the longer the period the more flexible the building and vice versa. Finding periods of a building requires solution of matrix eigenvalue problem:

$$
\mathbf{K \Phi}=\lambda \mathbf{M \Phi},
$$

where $\mathbf{K}$ and $\mathbf{M}$ are mass and stiffness matrices, respectively which can be replaced by $\mathbf{m}_{b}$ and $\mathbf{k}_{b}$ for FB condition, $\mathbf{m}_{s b}$ and $\mathbf{k}_{s b}$ for SSI condition and $\mathbf{m}_{b s b}$ and $\mathbf{k}_{b s b}$ for SSSI condition. $\lambda$ and $\Phi$ are eigenvalues and eigenvectors, respectively. The eigenvalues $\left(\lambda_{i} \equiv\left(2 \pi / T_{i}\right)^{2}\right)$ are roots of characteristic equation:

$$
f(\lambda)=\operatorname{det}(\mathbf{K}-\lambda \mathbf{M})=0,
$$

where $f(\lambda)$ is a polynomial of order equal to number of DOFs of the system. Solution method for eigenvalue problem must be iterative in nature because it requires finding roots of polynomial $f(\lambda)$. Inverse vector iteration method is an effective, accurate and computationally efficient for buildings because $\mathbf{K}$ and $\mathbf{M}$ are usually narrowly banded matrices. This method gives the first modal period so called fundamental period of the building $\left(T_{1}\right)$. Shorter modal periods $\left(\mathrm{T}_{\mathrm{i}}\right)$ can be obtained by inverse vector iteration method with a shift to converge the solution to the next eigenvalue.

Fig. 3 indicates variation of first two modal periods of the building with different soil types. It is observed form the figure that the soil makes the modal periods longer. The softer the soil, the longer the period. Anyhow, the changes are greater for first modal period than the second one. Effect of softer soils can be imagined as an additional story below the building whereas effect of stiffer soils is negligible. Consequently, different responses are expected from the building if the soil is taken into account. It should be noticed that SSI effect on building modal period is greater than SSSI effect regardless of the mode number. SSSI interaction slightly mitigates soil effects on building period. 
Table 2. Values for SSSI parameters $(d / a \leq 0.5)$ (Mulliken, Karabalis 1998)

\begin{tabular}{l|c|c}
\hline & Horizontal & Rocking \\
\hline damping & $c_{b s b f}=0.204 \frac{1}{(2-v)} \frac{G a^{2}}{V_{s}}$ & $c_{b s b \phi}=0.204 \frac{1}{(1-v)} \frac{G a^{4}}{V_{s}}$ \\
\hline stiffness & $k_{b s b f}=\left(0.88\left(\frac{d}{a}\right)-0.967\right) \frac{1}{(2-v)} G a$ & $k_{b s b \phi}=\left(0.88\left(\frac{d}{a}\right)-0.967\right) \frac{1}{(1-v)} G a^{3}$ \\
\hline
\end{tabular}

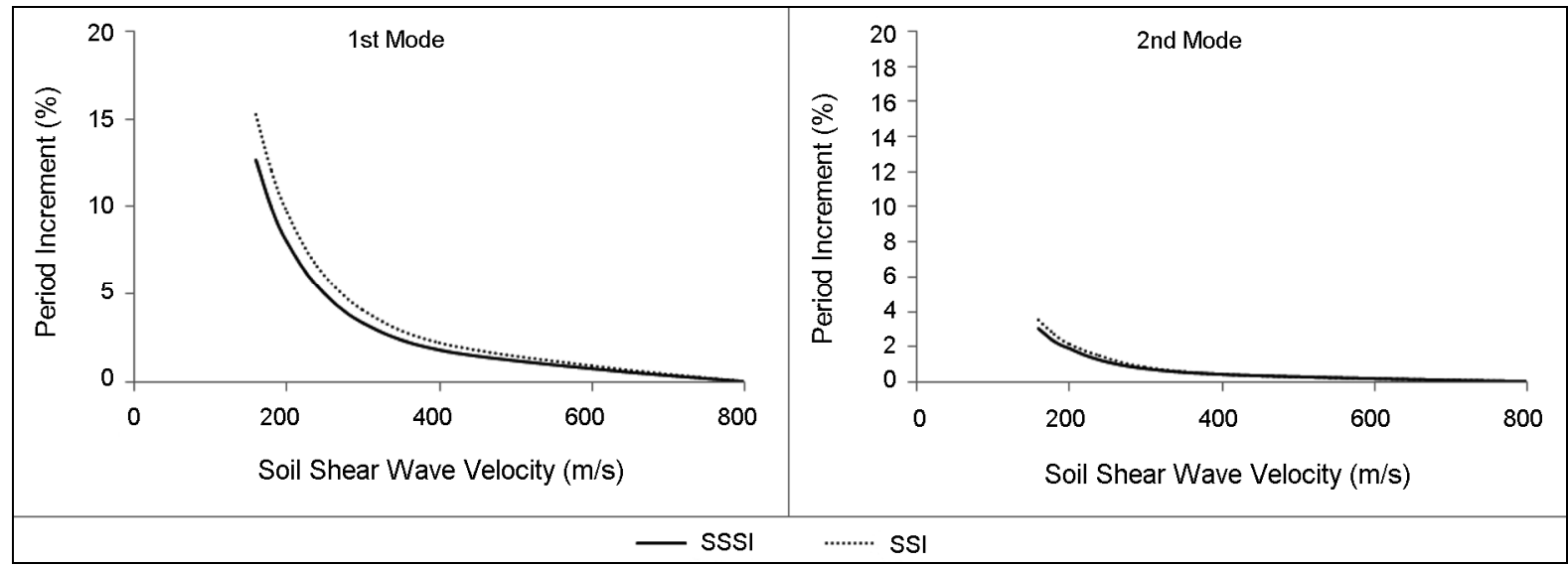

Fig. 3. Variation of modal periods of the building versus soil shear wave velocity

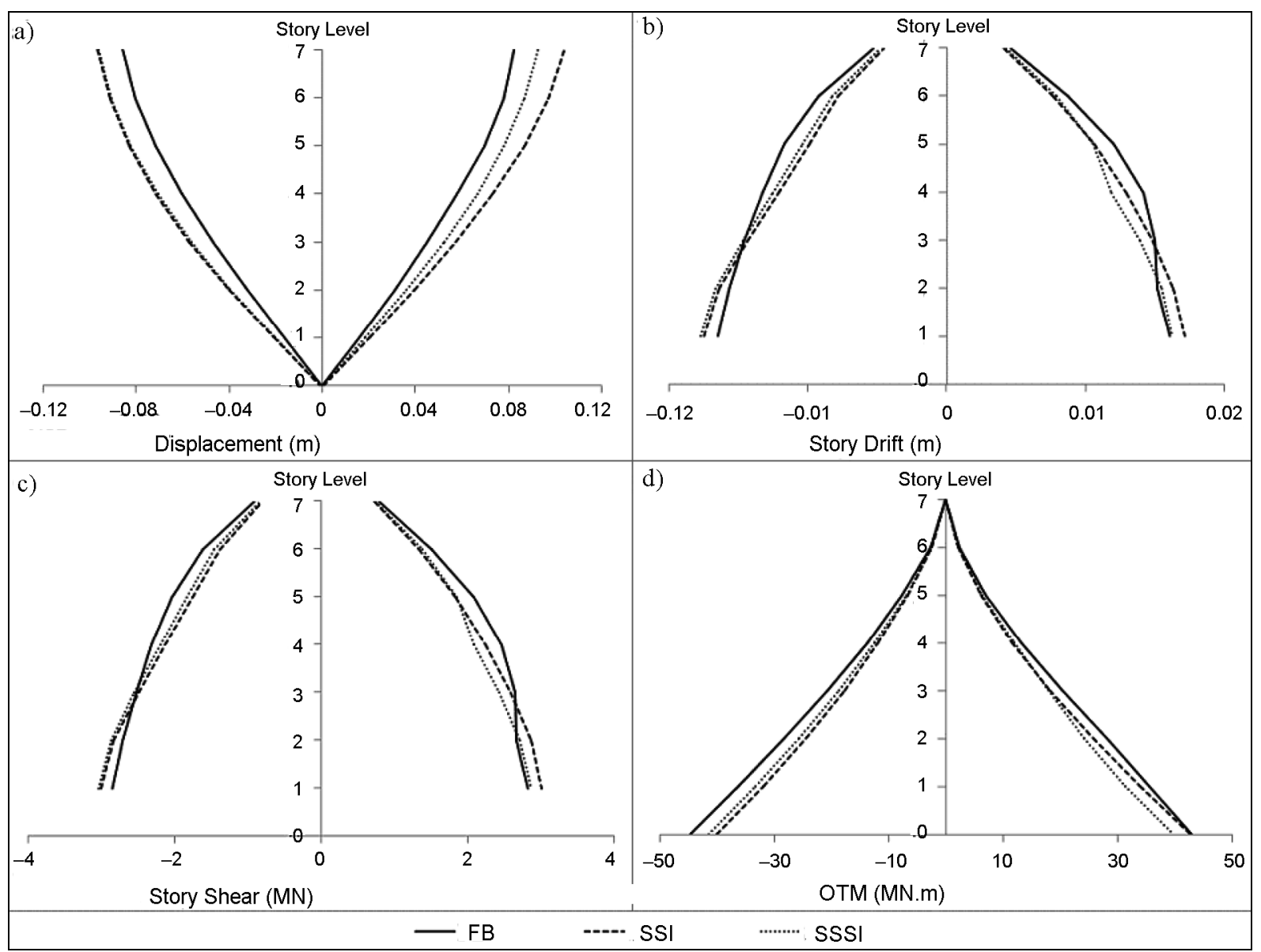

Fig. 4. Envelops of maximum responses of the building 


\subsection{Soil effects on building responses}

As it was shown in preceding section, the soil caused lengthening of the building period and consequently the building became more flexible. Thus, building responses are altered when the soil is taken into account. Earthquake induced envelops of maximum displacement, story drift, story shear and overturning moment (OTM) of the building are shown in Fig. 4.

There are three graphs related to different foundation conditions, FB, SSI and SSSI. For the SSSI case, response of only one building is displayed in the figure owing to the fact that twin buildings responses are similar. First of all it is obvious from this figure that soil alters distribution of response throughout the building. It is also observed from Fig. 4(a) that the soil causes the building experience larger displacements than FB condition. This increment is because of additional displacements imposed to the building by the soil. Displacement of building foundation (corresponding to level " 0 " in Fig. 4(a)) is zero for FB condition while is a non-zero value for SSI and SSSI conditions. This is very small displacement and in the order of millimeter while very effective in building responses particularly in lower stories. Displacements of lower stories are mainly affected by horizontal component of the soil while displacements of upper stories are increased due to rocking component of the soil. This explains the fact why story drifts are increased in lower stories while reduced in upper stories as it is seen in Fig. 4(b). First story displacement is increased due to horizontal component of the soil which causes larger relative displacements between foundation level and first story and consequently larger story drift. The trend is similar for second story while reverse for third and above stories. Relative displacements between two consecutive stories above the third level are reduced and consequently story drifts are decreased, because increments of displacement of upper stories are due to rocking component of the soil. Story shear of the building is affected by soil with a trend similar to the story drift because story shear is produced due to relative displacement between two consecutive stories. Again, story shear are increased for lower stories and decreased for upper stories as shown in Fig. 4(c). This means that base shear of the building and story shear of lower stories are increased due to soil effects which could be larger than the story shear considered in building design. Larger building base shear and different distribution of story drifts and story shears may result in building damage in lower stories because design of buildings are based on building codes which consider FB condition. Result of this study is perfectly consistent with observation of buildings damages during past earthquakes (Karantoni, Bouckovalas 1997; Schweier, Markus 2006; Tena-Colunga et al. 2008). Where the damage started from lower stories of the buildings and resulted in severe damages in lower stories for the buildings had located on soft soil layers. However, this phenomenon needs more investigations for all aspects of the problem to be disclosed. If necessary, seismic design of buildings in codes should be according to distribution of building responses based on soil types. Other result of considering soil effects is reduction of building OTM. This is due to the fact that story shears are reduced in upper stories and their contribution in building OTM is much more than story shears in lower stories.

\subsection{SSI and SSSI effects}

It was earlier mentioned that response of any building is affected by its adjacent building through the soil so called SSSI effect. Comparison between effects of SSI and SSSI conditions indicates that SSI effect is more serious than SSSI effect where the buildings are close to each other (Fig. 4). Furthermore, Fig. 5 indicates response ratios of different soil conditions (SSSI/SSI) for different separation distances between twin buildings. In this figure, unit response ratio corresponds to building response due to SSI condition. Where the separation distance is small and twin buildings are close together SSSI condition mitigates influences of soil on building responses. The SSSI effects approach the SSI effect with increment of the distance between twin buildings. When the buildings stand against each other with a distance larger than half of the building width the SSSI and SSI effects are similar. Consequently, SSSI condition is beneficial in building design and should be considered where the buildings are close together.

With respect to building influential distance it seems that buildings in a row/group are mostly affected by their immediate adjacent buildings rather than other buildings. Therefore, effect of SSSI condition on middle buildings would be worth further investigating.

\subsection{Mass ratio effect}

It is undeniable that properties of adjacent buildings are not always as same as each other like twin buildings. Soil effects on buildings responses could be somewhat different when adjacent buildings have different masses. It is tried in this section to investigate soil effects on adjacent buildings with different masses. Anyhow other properties of buildings, stiffness and building width, are adjusted accordingly so periods of both buildings remain similar.

Fig. 6 indicates response ratios of different soil conditions (SSSI / SSI) for different mass ratios. In this figure, unit response ratio corresponds to building response due to SSI condition and unit mass ratio corresponds to adjacent buildings with similar masses (twin buildings). First of all, it is obvious in the figure that both buildings indicate exactly same responses for unit mass ratio. However buildings responses differ from each other where one building becomes heavier than the other. Response of heavier building due to SSSI condition approaches to its response due to SSI condition with increment of mass ratio. SSI and SSSI effects on response of heavier building are almost same for mass ratio of 10 . However trend is different for lighter building; a small change is visible for response ratio of lighter building with increment of mass ratio but responses due to SSSI and SSI conditions are distinguishable even for higher mass ratios. Therefore, it can be concluded that heavier building influences its adjacent lighter building while it is less affected by its adjacent lighter buildings. 


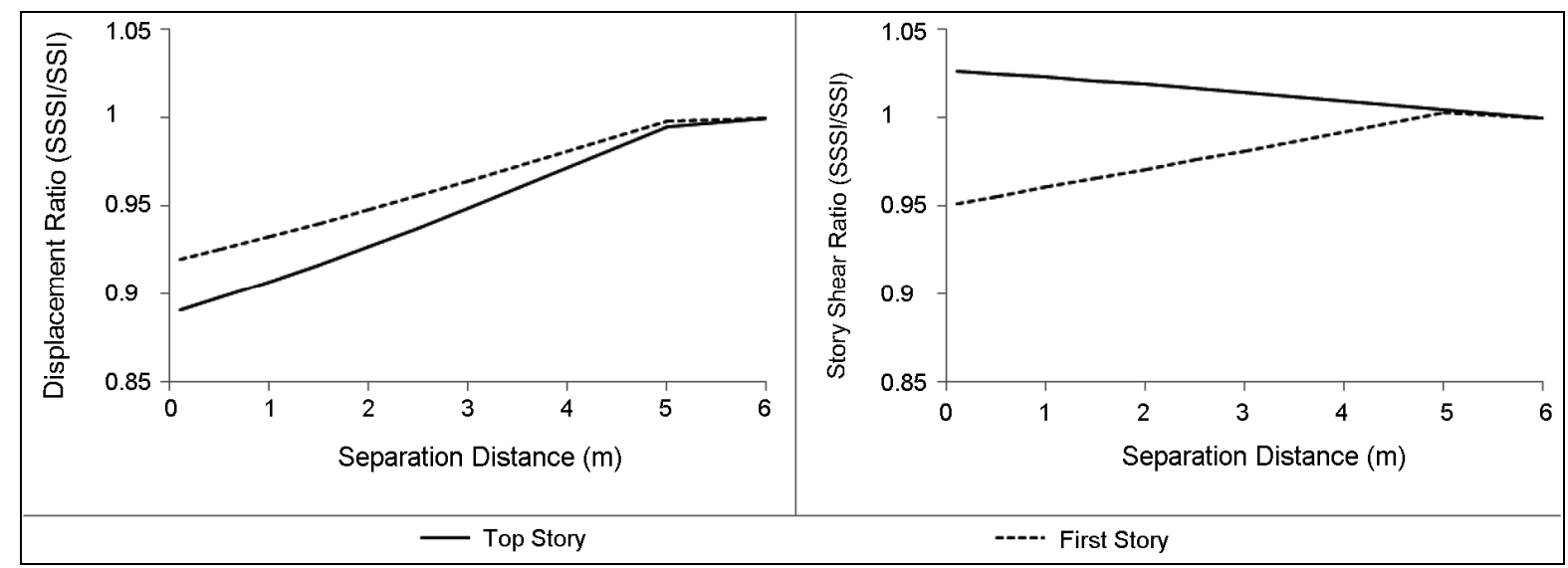

Fig. 5. Effect of separation distance between twin buildings

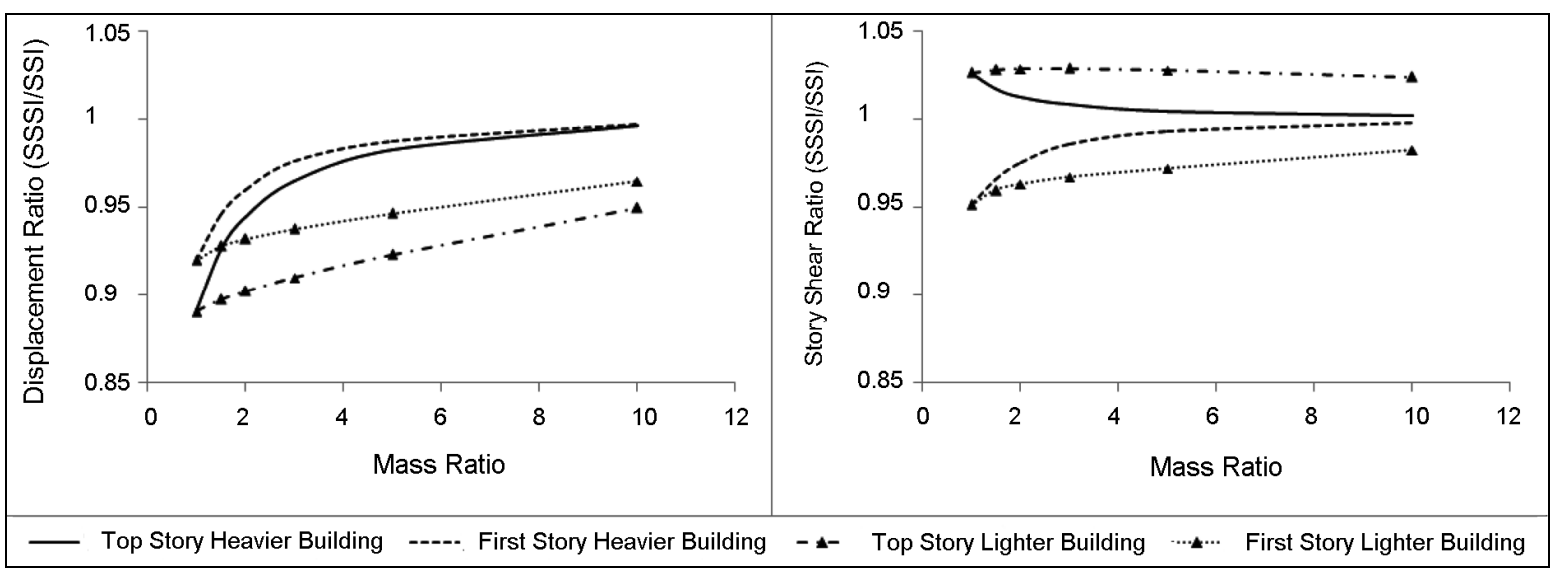

Fig. 6. Effect of mass ratio on building responses

\subsection{Building responses with different soil types}

Variations of first and top story responses with respect to different soil types are shown in Fig. 7. Maximum displacements of first and top stories are increased with lower shear wave velocities. The increment is slightly greater and its slope is sharper for top story than first story. This is because rocking deformation which affects the top story is very significant for softer soils while horizontal component of soils influences the first story which is important even for stiff soils. Variation of first and top story shears are in contrast with each other. Story shear of top story is decreased with reduction of soil shear wave velocity because it is affected by rocking component of the soil. In contrast, story shear of first story is increased with reduction of soil shear wave velocity because it is affected by horizontal component of the soil.

Effect of soil becomes negligible for relatively stiff soils with shear wave velocities around $400(\mathrm{~m} / \mathrm{s})$ and above. Responses of building finally converge to responses of FB condition in hard soils with shear wave velocity above $700(\mathrm{~m} / \mathrm{s})$.

There is a good agreement between changes of building responses and variation of building periods with soil, where the soil is soft the period is higher and displacements are larger. Although results are slightly more highlighted in SSI condition than SSSI condition, the trends are similar for SSI and SSSI conditions.
Fig. 8 indicates earthquake induced relative displacements and forces in soil for different soil types. Where the soil is soft, larger relative displacements and forces are happened. Relative displacements and forces in soil are reduced with increment of soil shear wave velocity. Soil responses changes are quite small for stiffer soils especially for earthquake induced soil forces.

\section{Conclusions}

It was concluded in this study that the soil caused the fundamental period of the building longer which resulted in larger displacements of building during earthquake excitations. In addition SSI/SSSI effects caused a significant change in distribution of building story drifts and story shears which may result in building damage in lower stories. This is because seismic induced story drifts and story shears were found to be greater in lower stories for SSI/SSSI condition than FB condition. Generally, SSI effects were observed to be more serious than SSSI effects particularly when the buildings were very close together. When the buildings have different masses heavier building influences its adjacent lighter building while it is less affected by its adjacent lighter buildings. Results of this study also indicated that buildings were significantly affected by soft to stiff soils while they were less influenced by hard soils. However, SSI/SSSI effects on building seismic behavior need more investigations for all 


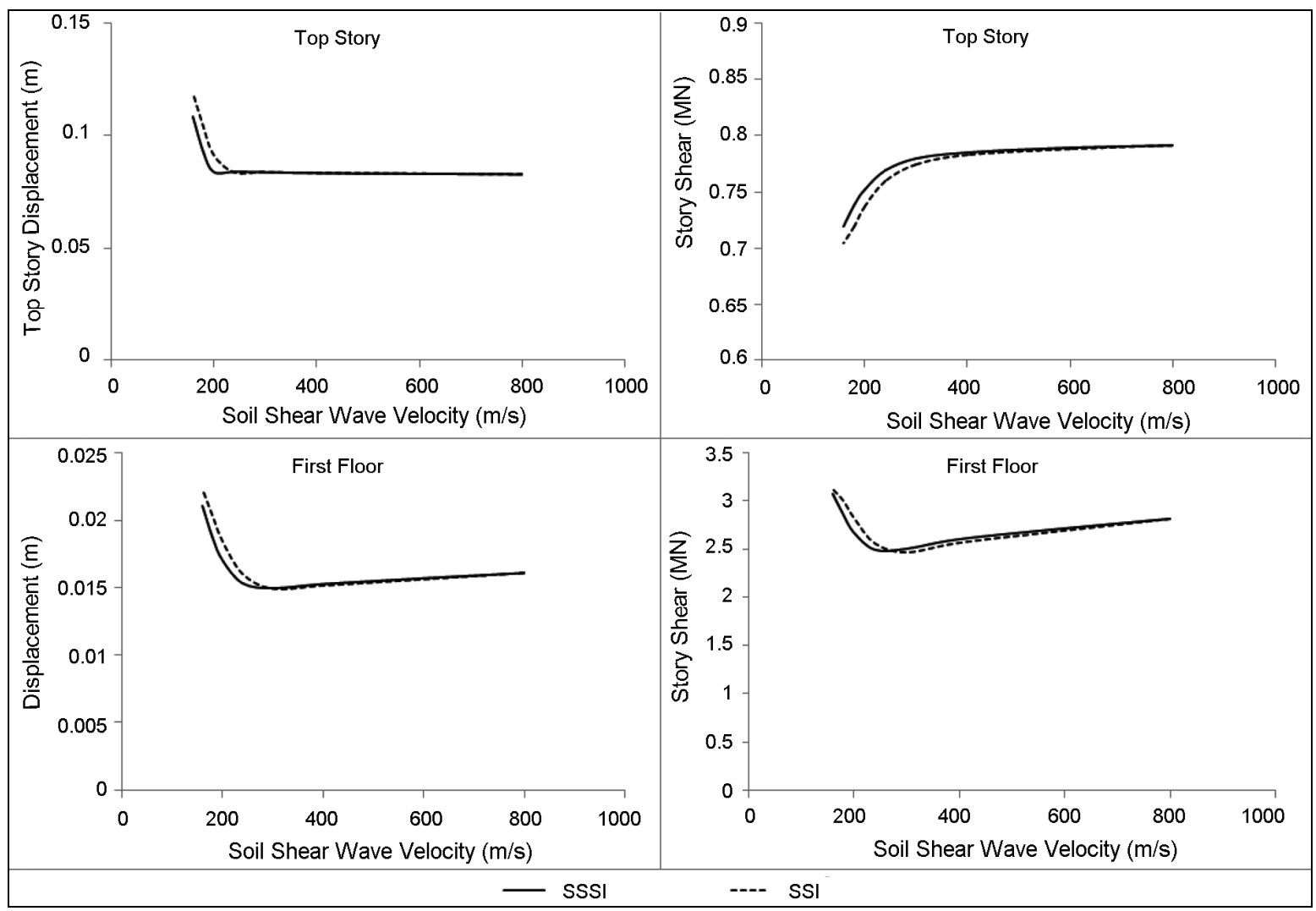

Fig. 7. Maximum story responses versus soil shear wave velocity

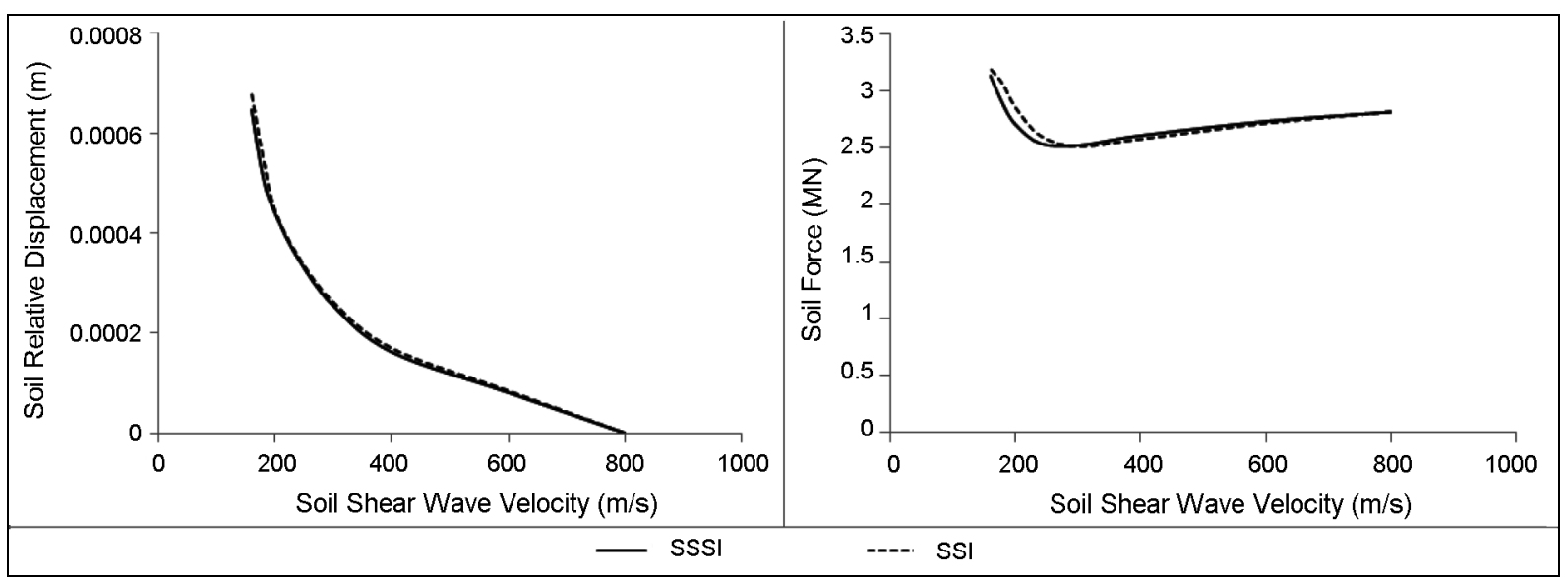

Fig. 8. Response of soil versus soil shear wave velocity

aspects of the problem to be disclosed. If necessary, seismic design of buildings in codes should be according to distribution of building responses based on soil type.

\section{References}

Chouw, N. 2002. Influence of soil-structure interaction on pounding response of adjacent buildings due to near-source earthquakes, Journal of Applied Mechanics 5: 543-553.

Dutta, S. C.; Bhattacharya, K.; Roy, R. 2004. Response of lowrise buildings under seismic ground excitation incorporating soil-structure interaction, Soil Dynamics and Earthquake Engineering 24(12): 893-914.

http://dx.doi.org/10.1016/j.soildyn.2004.07.001
Gallipoli, M. R.; Mucciarelli, M.; Ponzo, F.; Dolce, M.; D'Alema, E.; Maistrello, M. 2006. Buildings as a seismic source: analysis of a release test at Bagnoli, Italy, Bulletin of Seismological Society of America 96(6): 2457-2464. http://dx.doi.org/10.1785/0120060015

Gazetas, G. 1983. Analysis of machine foundation vibrations: state of the art review, Soil Dynamics and Earthquake Engineering 2(1): 2-42.

http://dx.doi.org/10.1016/0261-7277(83)90025-6

Gupta, V. K.; Trifunac, M. D. 1991. Seismic response of multistoried buildings including the effects of soil-structure interaction, Soil Dynamics and Earthquake Engineering 10(8): 414-422.

http://dx.doi.org/10.1016/0267-7261(91)90056-6 
Karantoni, F. V.; Bouckovalas, G. 1997. Description and analysis of building damage due to Pyrgos, Greece earthquake, Soil Dynamics and Earthquake Engineering 16(2): 141150. http://dx.doi.org/10.1016/S0267-7261(96)00035-8

Kausel, E. 2010. Early history of soil-structure interaction, Soil Dynamics and Earthquake Engineering 30(9): 822-832. http://dx.doi.org/10.1016/j.soildyn.2009.11.001

Lehmann, L.; Antes, H. 2001. Dynamic structure-soil-structure interaction applying the symmetric Galerkin Boundary Element Method (SGBEM), Mechanics Research Communications 28(3): 297-304.

http://dx.doi.org/10.1016/S0093-6413(01)00177-X

Matthees, W.; Magiera, G. 1982. A sensitivity study of seismic structure soil structure interaction problems for nuclear power plants, Nuclear Engineering and Design 73(3): 343-363.

http://dx.doi.org/10.1016/0029-5493(82)90011-5

Mulliken, J. S.; Karabalis, D. L. 1998. Discrete model for dynamic through-the-soil coupling of 3D foundations and structures, Earthquake Engineering and Structural Dynamics 27(7): 687-710. http://dx.doi.org/10.1002/(SICI) 1096-9845(199807)27:7<687::AID-EQE752>3.0.CO;2-O

Newmark, N. M. 1959. A method of computation for structural dynamics, Journal of the Engineering Mechanics Division ASCE 85(7): 67-94.

Novak, M.; El Hifnawy, L. 1983. Damping of structures due to soil structure interaction, Journal of Wind Engineering and Industrial Aerodynamics 11(1-3): 295-306. http://dx.doi.org/10.1016/0167-6105(83)90108-3

Padrón, L. A.; Aznárez, J. J.; Maeso, O. 2009. Dynamic structure soil structure interaction between nearby piled buildings under seismic excitation by BEM-FEM model, Soil Dynamics and Earthquake Engineering 29(6): 10841096. http://dx.doi.org/10.1016/j.soildyn.2009.01.001
Parmelee, R. A.; Perelman, D. S.; Lee, S.-L. 1969. Seismic response of multiple-storey structures on flexible foundations, Bulletin of Seismological Society of America 59(3): 1061-1070.

Rambabu, K. V.; Allam, M. M. 2007. Response of an openplane frame to multiple support horizontal seismic excitations with soil-structure interaction, Journal of Sound and Vibration 299(1-2): 388-396. http://dx.doi.org/10.1016/j.jsv.2006.07.008

Rohanimanesh, M. S. 1994. Mutual pounding of structures during strong earthquakes. PhD. thesis, Virginia: Virginia Polytechnic Institute and State University.

Tena-Colunga, A.; Correa-Arizmendi, H.; Luna-Arroyo, J. L.; Gatica-Avilés, G. 2008. Seismic behavior of codedesigned medium rise special moment-resisting frame RC buildings in soft soils of Mexico City, Engineering Structures 30(12): 3681-3707. http://dx.doi.org/10.1016/j.engstruct.2008.05.026

Schweier, C.; Markus, M. 2006. Classification of collapsed buildings for fast damage and loss assessment, Bulletin of Earthquake Engineering 4(2): 177-192. http://dx.doi.org/10.1007/s10518-006-9005-2

Shakib, H.; Fuladgar, A. 2004. Dynamic soil-structure interaction effects on the seismic response of asymmetric buildings, Soil Dynamics and Earthquake Engineering 24(5): 379-388. http://dx.doi.org/10.1016/j.soildyn.2004.01.002

Wang, S.; Schmid, G. 1992. Dynamic structure-soil-structure interaction by FEM and BEM, Computational Mechanics 9(5): 347-357. http://dx.doi.org/10.1007/BF00370014

Sadegh NASERKHAKI. Lecturer of the Sama Technical and Vocational Training College at the Islamic Azad University (IAU), Karaj Branch, Iran. He has been a Professional Engineer in Tehran province, Iran since 2008. His research interests include earthquake engineering, soil-structure interaction and analytical and numerical methods in civil engineering.

Hassan POURMOHAMMAD. Assistant Professor of the Civil Engineering Department at the Islamic Azad University (IAU), Karaj Branch, Iran, where he has been an active faculty member since 2000. He was research manager of Engineering Faculty from 2008 to 2009. He has been a Professional Engineer (P. Eng.) in Tehran province, Iran since 2000. He is author of a book published by IAU Press in 2011 and more than 15 papers published in journals and international conference proceedings. His research interests include earthquake engineering, passive structural control, structural dynamics, and earthquake disaster risk management. 